\title{
Geographic structure of genetic variation in the widespread woodland grass Milium effusum L. A comparison between two regions with contrasting history and geomorphology
}

\author{
Torbjörn Tyler
}

\begin{abstract}
Allozyme variation in the forest grass Milium effusum L. was studied in 21-23 populations within each of two equally sized densely sampled areas in northern and southern Sweden. In addition, 25 populations from other parts of Eurasia were studied for comparison. The structure of variation was analysed with both diversity statistics and measures based on allelic richness at a standardised sample size. The species was found to be highly variable, but no clear geographic patterns in the distribution of alleles or in overall genetic differentiation were found, either within the two regions or within the whole sample. Thus, no inferences about the direction of postglacial migration could be made. Obviously, migration and gene flow must have taken place in a manner capable of randomising the distribution of alleles. However, there were clear differences in levels and structuring of the variation between the two regions. Levels of variation, both in terms of genetic diversity and allelic richness, were lower in northern Sweden as compared with southern Sweden. In contrast, different measures of geographic structure all showed higher levels of population differentiation in the northern region. This is interpreted as due to different geomorphological conditions in the two regions, creating a relatively continuous habitat and gene flow in the southern region as compared with the northern region where the species, although common, is confined to narrow and mutually isolated corridors in the landscape.
\end{abstract}

Key words: Milium effusum, allozymes, geographic differentiation, population fragmentation, allelic richness.

\begin{abstract}
Résumé : La variation alloenzymatique chez la graminée forestière Milium effusum L. a été étudiée chez 21-23 populations au sein de deux régions situées dans le Nord et le Sud de la Suède, les deux régions étant de taille semblable et ayant fait l'objet d'un échantillonnage important. De plus, 25 populations situées dans d'autres régions d'Eurasie ont été étudiées pour fins de comparaison. La structure de la variation a été analysée tant à l'aide de statistiques estimant la diversité q'à l'aide de mesures basées sur la richesse allélique au sein d'échantillons de même taille. Cette espèce s'est avérée très variable, mais aucune répartition géographique claire des allèles ou en matière de différenciation génétique n'a été observée, pas plus au sein des deux régions que pour l'ensemble de l'échantillon. Ainsi, aucune inférence quant à la direction de la migration post-glaciaire n'a pu être faite. Évidemment, de la migration et des échanges de gènes ont dû avoir lieu de façon à randomiser la distribution des allèles. Cependant, il y avait des différences claires quant au niveau et à la structuration de la variation entre les deux régions. La variation, tant en termes de diversité génétique que de richesse allélique, était plus faible dans le Nord de la Suède que dans le Sud. Par contre diverses mesures de la structure géographique ont montré un plus grand degré de différenciation de la population dans la région septentrionale. Ceci est interprété comme étant dû à des conditions géomorphologiques différentes au sein des deux régions. Cela aurait créé un habitat et un flux génique relativement continus au Sud par rapport à la situation au Nord où l'espèce, bien que répandue, est confinée dans d'étroits corridors isolés les uns des autres.
\end{abstract}

Mots clés : Milium effusum, alloenzymes, différenciation géographique, fragmentation d'une population, richesse allélique.

[Traduit par la Rédaction]

Received 26 March 2002. Accepted 6 August 2002. Published on the NRC Research Press Web site at http://genome.nrc.ca on 10 October 2002.

Corresponding Editor: B. Golding.

T. Tyler. ${ }^{1}$ Department of Systematic Botany, Lund University, Lund, Sweden.

${ }^{1}$ Present address: Department of Ecology, Systematic Botany, Ecology Building, Lund University, Sölvegatan 37, SE-223 62 Lund, Sweden (e-mail: torbjorn.tyler@sysbot.lu.se). 


\section{Introduction}

The various coacting forces shaping geographic patterns and distributions of neutral genetic variation may be divided into three categories: historic migration processes, processes with a basis in population genetics (including random processes), and deterministic processes determined by distributional edge effects. However, the patterns observed also largely depend on how genetic variation and differentiation are defined and measured.

Processes of migration and range expansion, e.g., during postglacial colonisation, are generally considered to reduce levels of genetic variation (Hewitt 1996). Colonising individuals will only be able to carry with them a fraction of the variation present in the source population. However, the reduction in variability of populations in recently colonised areas, as compared with refugial source populations, may be more or less pronounced, depending on the number of migrants involved, the number of consecutive steps in the migration process, the possibility for multiple waves of migration, and the speed of population growth in newly colonised areas (cf. Ibrahim et al. 1996). Loss of variation will act directly on the number of variants (i.e., allelic richness), whereas compound measures of genetic diversity may or may not decrease simultaneously (Nei et al. 1975; Comps et al. 2000). However, if different migrating populations from genetically differentiated sources come into secondary contact and mix, levels of genetic variation may increase in colonised areas as compared with the source populations (cf. Taberlet et al. 1998).

Population genetic processes are determined by levels of gene flow, population size dynamics, and the reproductive biology of a given species in a given environment. Traits promoting efficient gene flow between genets and populations generally increase levels of genetic variation and reduce geographic (i.e., between population) differentiation (Hamrick and Godt 1989). Within a particular species, climatic and geological factors influence the availability and quality of suitable habitats as well as the probability of successful reproduction. Population fragmentation in general reduces gene flow and effective population size, thereby reducing the potential to retain genetic variation and facilitating differentiation of local populations through genetic drift. Populations growing under suboptimal conditions are likely to suffer from a reduction of intrinsic growth potential and sexual reproduction and may be further subjected to strongly fluctuating population size, all factors known to decrease levels of genetic variation and increase population differentiation (Barrett and Kohn 1991). Clonal vegetative propagation may increase in relative importance in suboptimal habitats because either resources are too limited for sexual organs to develop, suitable pollinators are wanting, or flowers and fruits are destroyed during spells of coldness or drought (Gabrielsen et al. 1997). However, although rarely discussed, there are also deterministic forces acting on levels of variation in marginal populations. We may consider a hypothetical species with a vast stable geographic distribution. Within this distribution area, ecological properties change clinally such that the suitability of the habitat decreases continuously in all directions from the centre of the distribution area. This will lead to a situation where the pop- ulation density decreases and the distance between populations restricted to suitable microsites increases, omnidirectionally with increasing distance from the distribution centre. If it is assumed that $(i)$ either variation is initially evenly distributed among individuals throughout the distribution or new variation is introduced through mutation at equal rates throughout, (ii) all diaspores produced are equally likely to disperse over longer distances and over any such distance, and (iii) dispersal is equally likely in all directions throughout the distribution area, then selectively neutral variation will successively accumulate towards the distribution centre simply because geographically central populations will receive dispersants (carrying new variation) from more directions and more distances than marginal populations.

In the present investigation, I have chosen to study levels and patterns of allozyme variation in the widespread woodland grass Milium effusum L. in two regions of approximately equal size. In addition, all available material of the species from throughout its distribution range was studied. The two regions were so chosen as to represent areas with contrasting distribution of the species and its habitat, as well as different patterns of human influence. Further, the two regions do represent areas with different position in the species' total distribution and in relation to known postglacial migration routes for plants and animals. The species was selected among a large number of candidates representing widespread Scandinavian woodland herbs because it was shown in an initial study to contain more interpretable allozyme variation than most other candidates (unpublished data). The aims have been to ( $i$ ) study whether patterns of genetic differentiation within the areas can be explained by historic routes for migration and gene flow, (ii) relate differences between the two areas in levels and structure of genetic variation to the regional distribution of the species' populations and its habitat, (iii) attempt to trace routes of postglacial migration into the regions concerned, and (iv) study the behaviour of different measures of genetic variation and differentiation when applied to natural populations.

\section{Materials and methods}

\section{Species}

Milium effusum is a tall perennial rhizomatous broad-leaved grass that forms loose mats in shaded habitats. Propagation by seed is common also within closed stands, and ramets sampled a few metres apart, although seemingly belonging to the same stand, usually belong to different genets (personal observation). The approximately 1-m-high, wind-pollinated inflorescenses appear sparsely in midsummer. Seed set is usually good. The achenes are smooth, approximately $1.5 \mathrm{~mm}$ in size, and show no apparent adaptations for any particular means of dispersal. The common form of the species has a chromosome complement of $2 n=28$ and probably has a tetraploid origin but shows a normal diploid meiotic pattern (Bennet and Thomas 1991). A diploid chromosome number of $2 n=14$ is known from the literature (Sokolovskaya and Strelkova 1960), but the vast majority of counts from all parts of the distribution area have revealed the tetraploid number (cf. Bennet and Thomas 1991; Bennet 
Fig. 1. Map of Europe indicating the geographic position of the analysed Milium effusum populations. Population 8 from the Altai Mountains in central Asia is located outside the map.

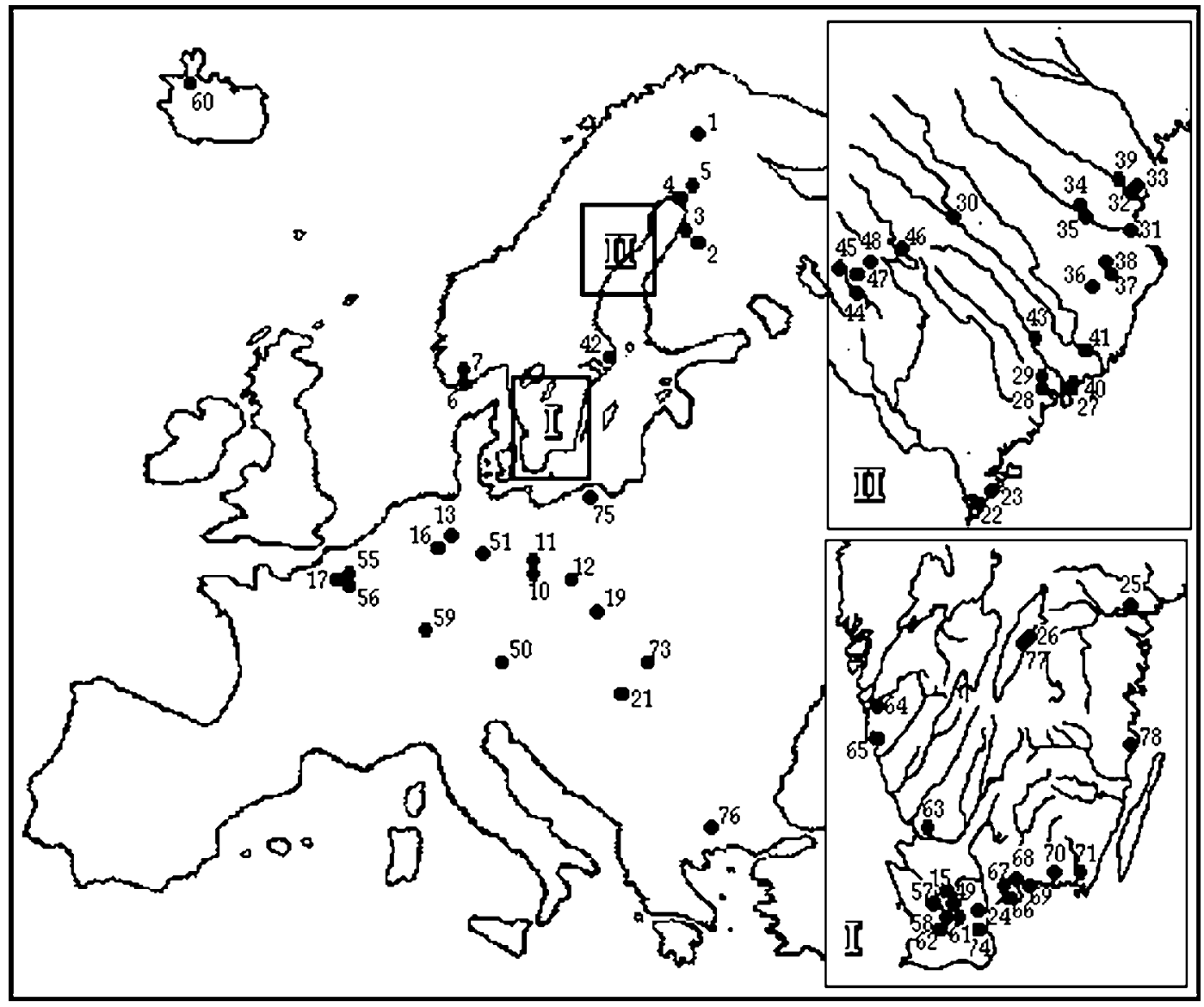

and Bennet 1992). In Europe, M. effusum grows in nemoral and boreal forests on neutral or mildly acidic soils. It is favoured by moving subsoil water and may under such condition occur in fairly light open habitats, but it can also be found in dry situations in closed forests. Except for forests on strongly acid and base-poor soils, M. effusum can be found in virtually any forest community in Scandinavia as well as on riverbanks and in lakeshore thickets. It thrives well in traditionally managed wooded hay meadows and it was probably formerly common in such habitats, but it has never been intentionally cultivated in Scandinavia. The species is widespread and common in most parts of Scandinavia and reaches the timberline in the Scandes Mountains but is much less common in areas with predominantly siliceous bedrock and acid moraines. In such areas, the regional population is generally strongly fragmented and local populations are defined to limited sites with favourable geomorphological conditions. The total distribution of the species covers almost all of Europe, excluding only the southernmost dry regions, and extends through the taiga belt of central Asia to Japan and Kamchatka. It is also found in the northeastern parts of the American continent (Hultén and Fries 1986) but is nowadays mostly rare and declining there (Dawn Foglia, New York, personal communication). Apart from the typical race, a morphologically deviating but poorly understood race is known from the mountains of eastern Europe (subspecies alpicola (Chrek) Sóo).

\section{Regions}

One region in southern Sweden and one in northern Sweden were chosen for intense comparative investigation (Fig. 1). These regions are of approximately equal size. The northern region represents the provinces of Angermanland, Västerbotten, and Åsele Lappmark, the largest distance between any two sampled populations being $285 \mathrm{~km}$. The southern region represents the provinces Skåne, Halland, Småland, Blekinge, and Östergötland, the largest distance between any two sampled populations being $345 \mathrm{~km}$.

The north Swedish region is a sparsely populated area of boreal conifer forest (sometimes referred to as "western taiga"). The geography is largely characterised by rivers running towards the southeast from the Scandes Mountains to the Baltic (cf. Fig. 1). The river valleys contain fertile fluvial deposits, and ultrabasic bedrock is often exposed along their often high and steep sides. In contrast, the areas in between the rivers are mostly characterised by coarse acid moraines and outcrops of hard siliceous bedrock. The large river valleys hold relatively dense human populations and, in particular in the past, human trade and transport have almost exclusively taken place along the main rivers. Plant species demanding more fertile and base-rich soil are generally common, with almost continuous populations in the river valleys, but are rare and fragmented in the intervening areas, and this is true for M. effusum as well (Stefan Ericson, Umeå, Sweden, personal communication). This region was 
the last lowland region to deglaciate after the last ice age. It became available for colonisation by plants and animals approximately 5000 years later than did southern Sweden (Björck 1995). In several animal species, populations migrating into Scandinavia from both western European refugia and refugia further to the east appear to have met precisely in this area (Taberlet et al. 1998).

The south Swedish region consists of a central highland area that slopes in all directions towards (coastal) lowland plains. As compared with northern Sweden, the human influence on the landscape is much larger and has a much longer history. The coastal plains are generally densely populated, deforested, and intensively used for agriculture, whereas the central highland, which has largely been used for extensive pastures in the past, is today mostly covered by coniferous forest on coarse and acid moraines. The surrounding broad zone of "slope areas" as well as some ridges on the coastal plains are relatively highly sculptured and dominated by nemoreal deciduous forest on relatively fertile soils. Demanding woodland species are generally widespread and common in these slope areas, and $M$. effusum occurs in almost every $25-\mathrm{km}^{2}$ area here (unpublished information kindly made available by the floristic inventory projects of the provinces of Skåne, Halland, Blekinge, and Småland). The whole area has been inhabited by humans for more than 10000 years and there are no major geographic barriers to human trade and transport.

\section{Sampling}

Twenty-one populations were sampled from the south Swedish region and 23 populations from the north Swedish region (Fig. 1). To investigate the pattern of genetic variation at a larger geographic scale, and the genetic context of the two intensely studied regions, material from 25 populations from Europe and one population from the Altai Mountains in central Asia was also analysed.

Living plant material for enzymatic analyses was obtained from three different sources. Some Swedish populations as well as some populations from other areas were sampled as adult plants directly in the field. In these cases, 20-25 ramets growing $>3 \mathrm{~m}$ apart were sampled from each population. Either ramets were transported to Lund and grown in a greenhouse prior to analyses or leaf material appropriate for enzyme extraction was sampled directly in the field. The remaining Swedish populations were sampled as seeds in a controlled manner. In these cases, mixed samples of seeds from at least 25 different inflorescensces, growing $>3 \mathrm{~m}$ apart, were collected from each population. The seeds were germinated in a greenhouse at Lund and, whenever available, the green parts of 24 seedlings were chosen at random for enzyme extraction. Most material from outside the two intensely investigated areas in northern and southern Sweden was obtained as bulk seed samples from local botanists or through the international seed-exchange system of the botanic gardens. These seeds originated from natural populations, but information about the sampling technique is usually wanting. Whenever possible, 24 seedlings were raised and analysed from these seed samples, but in several cases, only 8-15 living seedlings were obtained. In total, 1377 individuals from 69 populations were sampled.

\section{Enzyme electrophoresis}

Protocols for extraction, starch gel electrophoresis, and staining follow Tyler et al. (2002). Eight enzyme systems with a total of 14 polymorphic loci were analysed: three loci of PGI (EC 5.3.1.9), two loci of each of AAT (EC 2.6.1.1), DIA (EC 1.6.99), TPI (EC 5.3.1.1), SKD (EC 1.1.1.25), IDH (EC 1.1.1.42), and PGM (EC 5.4.2.2), and one locus of 6PGD (EC 1.1.1.44).

All enzyme stainings revealed products of more loci than usually found in diploid graminoides (personal observation), and in many cases, "alleles" (i.e., gene products with identical electrophoretic mobility) were shared between loci, although mostly in highly different relative frequencies. This is most probably due to an ancient allopolyploid origin of the species as previously suggested by Bennett and Thomas (1991) based on C-banding patterns. However, although gel interpretation in some cases became complicated owing to shared alleles and loci with overlapping mobilities, the electrophoretic patterns observed were consistent with a diploid mode of inheritance. At some loci with shared alleles, it was impossible to distinguish homozygotes from heterozygotes for some rare combinations of alleles. For this reason, I have refrained from calculating any measures based on observed heterozygosity. However, these ambiguities can, at most, have had a minor influence on the results as far as frequencies of alleles are concerned and, keeping in mind the general questions of geographic differentiation addressed here, these ambiguities were considered insignificant. All interpretation problems could have been avoided by treating the alleles as dominant markers, but this would have caused significant loss of information as compared with the original (codominant) data set.

\section{Data analysis}

Allele frequencies at all loci and in all populations as well as in the regional populations of the north and south Swedish regions were computed. These frequencies were illustrated on geographic maps and used to calculate genetic Cavalli-Sforza chord distances (CSCD) (Cavalli-Sforza and Edwards 1967) between all populations. The different genetic distance measures commonly used have been shown to give essentially the same result when compared under different conditions (Wiens 2000). However, CSCD puts relatively greater importance on the distribution of low-frequency alleles, as may be desired when patterns hypothesised to be shaped mainly by genetic drift are the main concern (cf. Konnert and Bergman 1995; T. Tyler, unpublished data). Two-dimensional nonmetric multidimensional scaling (MDS) (Kruskal 1964a, 1964b) based on the CSCD were performed and the genetic patterns revealed were illustrated on geographic maps. MDS produces an ordination of populations where the distances between populations have a monotone relationship to the original distances. As compared with the more commonly used method of principal components analyses (PCO), MDS does not require that the ordination as a whole explains a maximum share of the original variation. Because of this difference, MDS tends to reproduce the distances between the more similar populations more faithfully than does PCO. All of these calculations were made using the software package NTSYS-pc (Rohlf 1994). 
Fig. 2. MDS plot based on Cavalli-Sforza chord distances between all pairs of Milium effusum populations (stress: 0.392). Population numbers refer to Fig. 1; open numbers refer to populations in southern Sweden (region I in Fig. 1), solid numbers refer to populations in northern Sweden (region II in Fig. 1), and italicized numbers refer to populations from outside these more intensely sampled regions. Large symbols and dashed lines indicate the delimitation and representation of subclusters in Fig. 3.

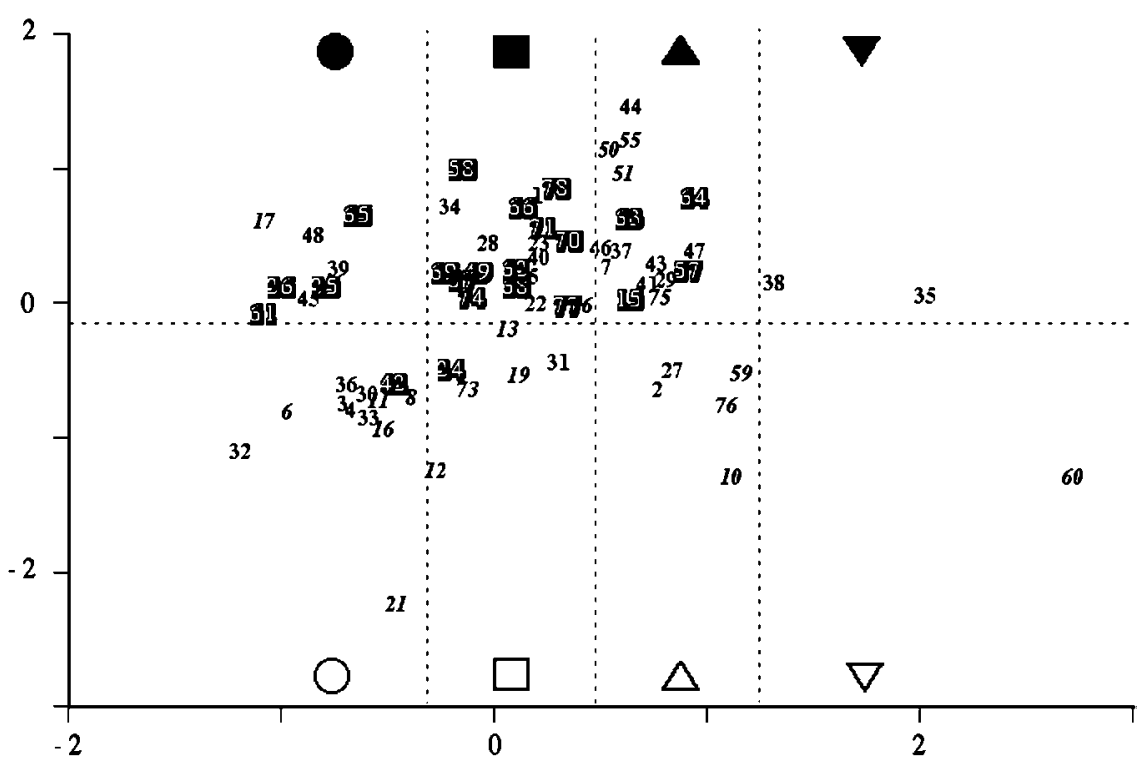

Within the north and south Swedish region, the observed numbers of every allele in each population were used to calculate genetic diversity $(H)$ and its between-population component $\left(G_{\mathrm{ST}}\right)$ (Nei 1973) as well as allelic richness at a standardised sample size $\left(A_{[g]}\right)$ and its partitioning among populations $\left(A_{\mathrm{ST}}=1-\left(A_{\mathrm{S}}-1\right) /\left(A_{\mathrm{T}}-1\right)\right.$, where $A_{\mathrm{S}}$ is the mean within-population $A_{[g]}$ and $A_{\mathrm{T}}$ is the total $A_{[g]}$ of the data set (Petit et al. 1998)). These calculations were made using the program CONTRIB written by Rémy Petit and downloaded from www.pierroton.inra.fr/genetics/labo/Software/. This program uses the method of rarefaction (Hurlbert 1971) to calculate allelic richness at a given standard sample size as described by Petit et al. (1998). The standard sample-size $(g)$ was put at 24 , since this was the smallest actual sample size of any investigated population.

\section{Results}

A total of 41 alleles were found at the 14 analysed polymorphic loci (2.9 alleles per polymorphic locus) in the whole material comprising 2754 haploid genomes. Eight alleles were restricted to single populations; one of these was found in the north Swedish region and two in the south Swedish region. Among the remaining low-frequency alleles, all were found in two or more geographically distant populations and none was restricted to a single region or to a few neighbouring populations. In general, all alleles showed highly patchy, or seemingly random, geographic distributions (not shown). Allele frequencies of all populations can be obtained upon request from the author.

Interpopulational genetic distances (CSCD), when illustrated on maps, did not reveal any discernible geographic patterns (not shown). Small $(<1.5)$ as well as large $(>5)$ genetic distances were found both among pairs of geographically adjacent populations (a few kilometres apart) and among pairs of populations spanning the whole European continent (not shown). Lines connecting the genetically most similar populations also did not produce any geographically meaningful pattern. This lack of genetic-geographic pattern was consistently observed both within the two Swedish regions and throughout the whole material. However, genetic distances were generally somewhat smaller between Scandinavian populations than both between extra-Scandinavian populations and between these and the Scandinavian populations. The largest genetic distances $(\mathrm{CSCD} \approx 10-14)$ were found between the Icelandic and Slovenian populations (populations 60 and 21) on one hand and all other populations on the other.

The regional gene pools of the north Swedish and south Swedish regions were very similar, the CSCD between the two regions being only 0.44 . Most similar to both Swedish regional populations were population 5 in northern Finland and population 13 in western Germany (CSCD $=0.9-1.4$ ). The genetic distances (CSCD) between both Swedish regional populations and the various other populations were generally in the range 1.5-3.0 and no particular geographic patterns in these distances could be revealed (not shown). Most genetically distant from the Swedish regional populations were population 60 from Iceland $(\mathrm{CSCD}=6.3-8.8)$ and Slovenian population $21(\mathrm{CSCD}=5.1-5.9)$, whereas, e.g., the genetic distances to the remote central Asian population 8 were $\approx 3.0$.

Two-dimensional MDS based on CSCD genetic distances distributed the populations fairly evenly along the two axes (Fig. 2). No distinct subclusters were formed, but a few populations, e.g., Slovenian population 21, Icelandic population 60 , and north Swedish population 35, appeared as distant outliers. There was a slight tendency for extra-Scandinavian populations to cluster in the outer regions (in all directions) of the ordination plot, outside a more tight central cluster containing most of the Scandinavian populations (Fig. 2). Furthermore, most populations from the eastern part of the 
Fig. 3. Geographic distribution of Milium effusum populations referred to eight arbitrarily delimited subclusters in the MDS analyses. See Fig. 2 for further explanation. Central Asian population 8, which belongs to the subcluster denoted by an open circle, is located outside the map.

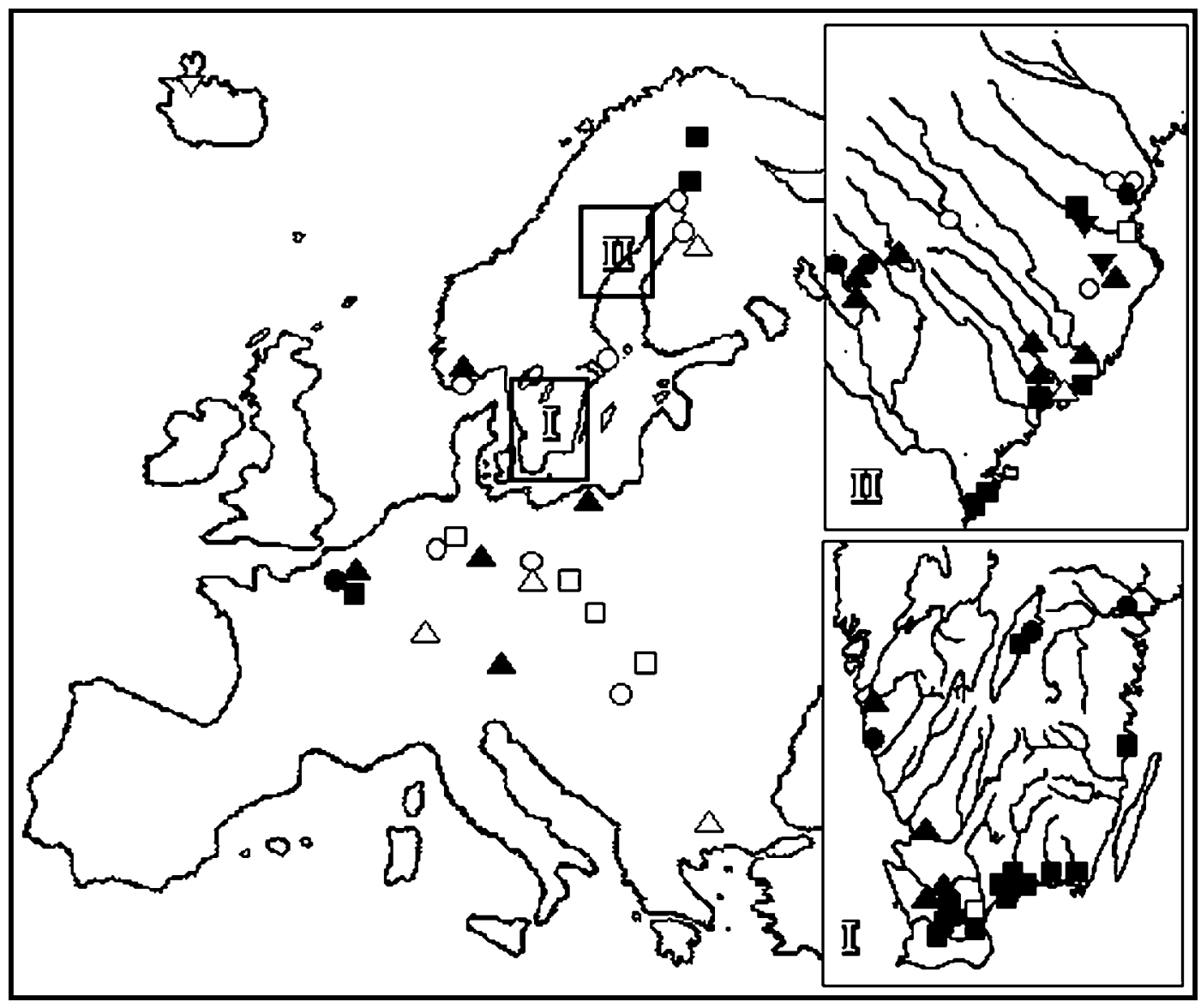

south Swedish region clustered tightly together (around zero on both axes in the MDS plot), but several populations from other parts of Europe were also included in this group. Although several attempts were made to differently divide the MDS plot into subclusters and illustrate the geographic distribution of these subgroups, no geographic patterns, apart from the tendencies mentioned above, were revealed. The result of one of these attempts is shown in Fig. 3.

Allelic richness $(A)$ as well as genetic diversity $(H)$, both within populations and within regions, were higher in the south Swedish region than in the north Swedish region (Table 1). Owing to insufficient sampling and incomparable sampling design, comparable measures for the central European populations could not be calculated, but no apparent differences in levels of genetic variation between these and the Scandinavian populations were revealed upon inspection. In spite of the larger sample size, the observed number of alleles per locus $\left(A_{\text {obs }}\right)$ was considerably lower in the north Swedish region as compared with the south Swedish region. However, since many of the additional alleles found in the south Swedish region were very rare, this difference became less apparent upon standardisation to a sample size of 24 $\left(A_{\mathrm{T}[24]}\right)$. In contrast, all measures of population differentiation, regardless of whether based on genetic distance measures (mean CSCD), allelic richness $\left(A_{\mathrm{ST}}\right)$, or genetic diversity $\left(G_{\mathrm{ST}}\right)$, were 1.5-2 times higher in the north Swed-
Table 1. Summary of diversity statistics for Milium effusum in southern Sweden (820 haplotypes from 21 populations; region I in Fig. 1) and in northern Sweden (1052 haplotypes from 23 populations; region II in Fig. 1).

\begin{tabular}{lll}
\hline & Southern Sweden & Northern Sweden \\
\hline$H_{\mathrm{T}}$ & 1.94 & 1.78 \\
Mean $H_{\mathrm{S}}$ & 0.099 & 0.06 \\
$G_{\mathrm{ST}}$ & 0.29 & 0.53 \\
$A_{\mathrm{T}[24]}$ & 1.5 & 1.42 \\
Mean $A_{\mathrm{S}[24]}$ & 1.31 & 1.17 \\
$A_{\text {Tobs }}$ & 2.43 & 1.86 \\
$A_{\mathrm{ST}[24]}$ & 0.38 & 0.59 \\
Mean CSCD & 2.59 & 4.13 \\
\hline
\end{tabular}

Note: $H_{\mathrm{T}}$ is the total genetic diversity (Nei 1973) of the region, mean $H_{\mathrm{S}}$ is the mean (over loci and populations) within-population genetic diversity, $G_{\mathrm{ST}}$ is the proportion of the total genetic diversity explained by between-population differentiation (Nei 1973), $A_{\mathrm{T}[24]}$ is the total regional allelic richness (i.e., number of alleles per locus) at a standardized sample size of 24 , mean $A_{\mathrm{S}[24]}$ is the mean within-population number of alleles per locus at a standardized sample size of $24, A_{\text {Tobs }}$ is the observed number of allels per locus at the true sample size, $A_{\mathrm{ST}[24]}$ is the proportion of the total allelic richness explained by between-population differentiation (Petit et al. 1998), and mean CSCD is the mean Cavalli-Sforza chord distance (Cavalli-Sforza and Edwards 1967) between all pairs of populations in each region. 
ish region as compared with the south Swedish region (Table 1).

\section{Discussion}

The distribution of alleles and their frequencies were found to be very patchy at all investigated geographic scales. No alleles were confined to well-delimited geographic areas, and multivariate methods based on genetic distances did not show much genetic-geographic pattern (cf. Fig. 3). Except for a few deviant populations (see below), genetic distances between populations were even and no distinct subclusters were formed upon MDS analyses. This pattern is congruent with a situation where genetic drift in small populations, initial founder events, and rare but highly leptokurtic long-distance dispersal are the most important factors shaping the geographic structure of genetic variation. Similar (lack of) patterns have been found in other widespread woodland plants (Tyler et al. 2002; Tyler 2002a) but appear to be rare among other studied plant species. However, most studies hitherto undertaken have concentrated either on forest trees, which generally have extremely efficient gene flow with pollen, or on rare and threatened species with highly disjunct distributions. It may be speculated that patterns with locally differentiated and isolated populations founded by leptokurtic long-distance dispersers may become more common as more data on widespread and common herbs accumulate.

Within the north Swedish region, I expected to find some patterns of genetic differentiation following the main river valleys, but no such patterns were found. Either more gene flow has occurred between these narrow corridors than expected or strong local population differentiation through genetic drift has concealed any patterns of among-valley differentiation. Within the south Swedish region, MDS analyses produced what appears to be a nonrandom pattern of population differentiation (Fig. 3), but the pattern revealed has no evident biogeographical meaning and it is lost when populations from other areas are included.

However, there were large and congruent differences between the north Swedish and south Swedish regions in all measures of overall levels and structure of genetic variation (Table 1). All measures of levels of genetic variation $\left(H_{\mathrm{T}}\right.$, $H_{\mathrm{S}}, A_{\mathrm{T}}, A_{\mathrm{S}}$ ) were higher in the southern region as compared with the northern region. Since the genetic distance between the regional gene pools of these two areas was very small, the possibility that the gene pools compared originate from essentially different waves of immigration can be excluded. The northern population must have either lost more variation during immigration or failed to retain the variation once present, as compared with the southern region. It appears impossible to distinguish between these two processes and the true scenario may involve both. If Scandinavia was colonised mainly from refugia in southern Europe, as believed for most organisms, then the distance migrated to reach northern Sweden will have been considerably longer than to southern Sweden, and more variation might have been lost during repeated founder events. However, given the present-day total distribution of $M$. effusum, a postglacial scenario with immigration mainly from a refugium in western Asia seems equally possible. The deterministic effects of marginality outlined in the Introduction may have reduced levels of variation in the northern area. However, since the species' distribution extends further to the north from this region, and since these forces are probably relatively slow, effects of marginality appear unlikely as a major cause of the differences observed.

All measures of overall genetic differentiation of local populations $\left(G_{\mathrm{ST}}, A_{\mathrm{ST}}, \mathrm{CSCD}\right)$ were higher in the north Swedish region as compared with the south Swedish region. These estimates indicate lower overall levels of gene flow in the former area, which is consistent with expectations based on the more mosaic distribution pattern for the species, its habitat, as well as more restricted anthropogenic dispersal in this region. In the south Swedish region, the suitable habitat for this species is almost continuous over large areas and should have been even more widespread in the past. Anthropogenic dispersal with hay, either for commercial trade or with fodder for travellers' horses, may also have been important in this region. In the north Swedish region, the suitable habitat is continuous only along the river valleys. Most human transports have followed the same valleys, and horses with travellers were probably very rare in older times. Accordingly, it is plausible with lower levels of historic and present gene flow in the northern region, and this may be taken as an explanation for the overall lower levels of variation as well. Reduced levels of gene flow reduce effective population size, slow down the extinction-recolonization process, and increase the probability of loss of rare alleles. However, since M. effusum is a long-lived perennial, metapopulation dynamics are likely to be slow. Further, since the species is common in both regions, regional populations are certainly very large and the forces of genetic drift on a regional scale should have been weak.

Levels of overall population differentiation may also be related to the mean age of the populations. If genetic drift is the main driving force and is not contra-acted by gene flow, population differentiation should increase with time. However, if gene flow is efficiently balancing genetic drift, then the initial founder event may be the main cause of population differentiation, which will then decrease with time (Wade and McCauley 1988; Comps et al. 2000). Wright (1931) argued that if the number of migrants per generation $\left(N_{\mathrm{m}}\right)$ is larger than 1 , gene flow will efficiently counteract genetic drift and the number of migrants per generation may be calculated as $N_{\mathrm{m}}=1 / 4\left(1 / G_{\mathrm{ST}}-1\right)$. Applying this formula to M. effusum, the number of migrants per generation in both the north Swedish and south Swedish regions is far less than 1 ( 0.23 and 0.61 , respectively). Although this way of estimating $N_{\mathrm{m}}$ involves many unrealistic assumptions and is poorly adapted to natural situations (Bossard and Prowell 1998; Whitlock and McCauley 1999), the result might be taken as an indication that population differentiation in M. effusum is likely to increase with time. The larger overall population differentiation in northern Sweden as compared with southern Sweden can thus not readily be explained by the shorter time since deglaciation of the former area.

Most pairwise genetic distances between the both Swedish regions and populations from other areas were of approximately the same size and no geographic trends could be found. Likewise, the distribution of individual alleles also gave no clear indication about the geographic origin of the 
Swedish regional populations. Thus, no inferences about refugia and directions of postglacial migration could be made. However, it is noteworthy that the most geographically distant population, population 8 from the Altai Mountains in central Asia, was not more genetically distant than most other populations. There are still very few studies of genetic-geographic patterns in widespread Eurasian organisms, but a study in the forest grass Melica nutans L. (Tyler $2002 b$ ) including material from central Siberia revealed that populations from these areas are surprisingly genetically similar to European populations, and the same result has been reached for several species of fish (Bernatchez and Wilson 1998; Stepien et al. 1998; Nesbø et al. 1999). In Melica nutans, genetic distances between various proposed refugial populations in southern Europe were far greater than between the central Asian populations and most north European populations (Tyler 2002b). The information obtained so far is obviously too scarce to allow for any general conclusions, but these results point to the need to also include Asian material when studying genetic-geographic patterns and the phylogeography of European species.

The most genetically differentiated populations appeared to be population 60 from Iceland and population 21 from Slovenia. It may be speculated that the Icelandic populations may be more closely related to those in North America. However, the investigated material was received through the international seed-exchange system and its origin was given as "Iceland" only; thus, any conclusions based on this sample must be treated with the utmost care. Milium effusum is rare in North America, and although several attempts have been made, it has not been possible to obtain any samples from there. Slovenian population 21 was sampled in an area where the badly understood subspecies alpicola (Chrek) Sóo is known to occur. Since no adult plants were raised, it was not possible to tell which subspecies the material belonged to. However, it appears likely that some strongly differentiated genotypes occur in this region.

The different measures based on genetic distance (CSCD), allelic richness $(A)$, and genetic diversity $(H)$ all showed the same general pattern in M. effusum. This partly contradicts previous studies using empirical data (Comps 2000). Further, theoretical studies have shown that these measures may behave incongruently under a variety of assumptions (Chakraborty et al. 1988; Luikart et al. 1998; Wakeley 1998). It has been proposed that measures based on allelic richness and genetic diversity may under some circumstances show different pictures deserving different explanations (cf. Petit et al. 1998; Comps et al. 2000). Under theoretical conditions (assuming e.g., mutation-drift equilibrium), genetic diversity is strongly positively correlated with allelic richness (the number of different alleles per locus found at a given sample size; Chakraborty et al. 1980), but the most comprehensive study to date of the topic in a true species found a strong negative correlation between these two measures (Comps et al. 2000). Whereas allelic richness depends directly on the presence of alleles that, once lost, can only be regained through the very slow process of mutation, genetic diversity depends mainly on the evenness of frequencies of the most common alleles, which may increase as long as there are at least two alleles at a particular locus. Since the most prominent effect of genetic drift is the loss of low-frequency alleles, allelic richness should give a better indication of historic processes reducing the effective population size than does genetic diversity (Konnert and Bergman 1995; Luikart et al. 1998). Apart from the ambiguity concerning the relationship between genetic diversity and allelic richness discussed above, $G_{\mathrm{ST}}$, when used as a measure of average population differentiation, suffers from the fact that it does not differentiate between alleles. Whenever there are more than two alleles at a locus, genetic diversity, the measure on which $G_{\mathrm{ST}}$ is based, may have the same size in different populations even if they do not have a single allele in common. The $A_{\mathrm{ST}}$, based on standardised allelic richness but otherwise computed in conformity with $G_{\mathrm{ST}}$, largely depends on the distribution of rare alleles among populations and may thus give a better measure than $G_{\mathrm{ST}}$ of population differentiation caused by genetic drift, but this measure is also unable to differentiate between alleles. As an alternative, mean genetic distance, and there have been quite a number of such distance measures proposed in the past, may be used as a measure of population differentiation. However, there are still very few studies using these measures in a readily comparable way on the same data set, a practice that I believe should be strongly encouraged.

\section{Acknowledgements}

Although too many to be mentioned explicitly here, I am indebted to each and every colleague who has helped me by collecting seed material for the present study. Stefan Ericson is further thanked for giving important information about the occurence of M. effusum in northern Sweden. Mikael Hedrén gave valuable comments on previous versions of the manuscript. The study was financed by a grant from Uddenberg-Nordingska stiftelsen.

\section{References}

Barrett, S.C.H., and Kohn, J.R. 1991. Genetic and evolutionary concequences of small population size. In Genetics and conservation of rare plants. Edited by D.A. Falk and K.E. Holsinger. Oxford University Press, New York, N.Y.

Bennet, S.T., and Bennet, M.D. 1992. Variation in nuclear DNA amount between wild and cultivated populations of Milium effusum $(2 n=28)$. Genome, 35: 1050-1053.

Bennet, S.T., and Thomas, S.M. 1991. Karyological analysis and genome size in Milium (Gramineae) with special reference to polyploidy and chromosomal evolution. Genome, 34: 868-878.

Bernatchez, L., and Wilson, C.C. 1998. Comparative phylogeography of Nearctic and Palearctic fishes. Mol. Ecol. 7: 431-452.

Björck, S. 1995. A review of the history of the Baltic Sea, 13.0-8.0 ka BP. Quat. Int. 27: 19-40.

Bossard, J.L., and Prowell, D.P. 1998. Genetic estimates of population structure and gene flow: limitations, lessons and new directions. Trends Ecol. Evol. 13: 202-206.

Cavalli-Sforza, L.L., and Edwards, A.W.F. 1967. Phylogenetic analysis: models and estimation procedures. Am. J. Hum. Genet. 19: $233-257$.

Chakraborty, R., Fuerst, P.A., and Nei, M. 1980. Statistical studies on protein polymorphisms in natural populations. III. Distribution of allele frequencies and the number of alleles per locus. Genetics, 91: 1039-1063. 
Chakraborty, R., Smouse, P.E., and Neel, J.V. 1988. Population amalgation and genetic variation: observations on artificially agglomerated tribal populations of Central and South America. Am. J. Hum. Genet. 43: 709-725.

Comps, B., Gömöry, D., Letouzey, J., Thiébaut, B., and Petit, R.J. 2000. Diverging trends between heterozygosity and allelic richness during postglacial colonization in the European bech. Genetics, 157: 389-397.

Gabrielsen, T.M., Bachmann, K., Jacobsen, K.S., and Brochmann, C. 1997. Glacial survival does not matter: RAPD phylogeography of Nordic Saxifraga oppositifolia. Mol. Ecol. 6: 831-842.

Hamrick, J.L., and Godt, M.J.W. 1989. Allozyme diversity in plant species. In Plant population genetics, breeding and genetic variation in plants. Edited by A.D.H. Brown, M.T. Clegg, A.L. Kahler, and B.S. Weir. Sinauer Associates Inc., Sunderland, Mass. pp. 43-63.

Hewitt, G.M. 1996. Some genetic consequences of ice ages, and their role in divergence and speciation. Biol. J. Linn. Soc. 58: 247-276.

Hultén, E., and Fries, M. 1986. Atlas of North European vascular plants. Koeltz Scientific Books, Koenigstein, Germany.

Hurlbert, S.H. 1971. The nonconcept of species diversity: a critique and alternative parameters. Ecology, 52: 577-586.

Ibrahim, K.M., Nichols, R.A., and Hewitt, G.M. 1996. Spatial patterns of genetic variation generated by different forms of dispersal during range expansion. Heredity, 77: 282-291.

Konnert, M., and Bergman, F. 1995. The geographical distribution of genetic variation of silver fir (Abies alba) in relation to its migration history. Plant Syst. Evol. 196: 19-30.

Kruskal, J.B. 1964a. Multidimensional scaling by optimizing goodness of fit to a nonmetric hypothesis. Psychometrica, 29: 1-27.

Kruskal, J.B. 1964b. Nonmetric multidimentional scaling: a numerical method. Psychometrica, 29: 28-42.

Luikart, G., Sherwin, W.B., Steele, B.M., and Allendorf, F.W. 1998. Usefulness of molecular markers for detecting population bottlnecks via monitoring genetic change. Mol. Ecol. 7: 963-974.

Nei, M. 1973. Analysis of gene diversity in subdivided populations. Proc. Natl. Acad. Sci. U.S.A. 70: 3321-3323.

Nei, M., Maruyama, T., and Chakraborty, R. 1975. The bottleneck effect and genetic variability in populations. Evolution, 29: $1-10$.
Nesbø, C.L., Fossheim, T., Vøllestad, L.A., and Jakobsen, K.S. 1999. Genetic divergence and phylogeographic relationships among European perch (Perca fluviatilis) populations reflect glacial refugia and postglacial colonisation. Mol. Ecol. 8: 1387-1404.

Petit, R.J., El Mousadik, A., and Pons, O. 1998. Identifying populations for conservation on the basis of genetic markers. Conserv. Biol. 12: 844-855.

Rohlf, F.J. 1994. NTSYS-pc, numerical taxonomy and multivariate analysis system. Exeter Software, Setuaket.

Sokolovskaya, A.P., and Strelkova, O.S. 1960. Geographical distribution of polyploid species of plants in the Eurasiatic arctic. Bot. Zh. SSSR, 45: 369-381.

Stepien, C.A., Dillon, A.K., and Chandler, M.D. 1998. Genetic identity, phylogeography, and systematics of ruffe Gymnocephalus in the North American Great lakes and Eurasia. J. Gt. Lakes Res. 24: 361-378.

Taberlet, P., Fumagalli, L., Wust-Saucy, A.-G., and Cossons, J.-F. 1998. Comparative phylogeography and postglacial colonization routes in Europe. Mol. Ecol. 7: 453-464.

Tyler, T. 2002a. Geographical distribution of allozyme variation in relation to post-glacial history in Carex digitata, a widespread European woodland sedge. J. Biogeogr. 29: 919-930.

Tyler, T. 2002b. Broad-scale geographic patterns of genetic variation in Melica nutans, a widespread Eurasian woodland grass. Plant Syst. Evol. In press.

Tyler, T., Prentice, H.C., and Widén, B. 2002. Geographic variation and dispersal history in Fennoscandian populations of two forest herbs. Plant Syst. Evol. 233: 29-46.

Wade, M.J., and McCauley, D.E. 1988. Extinction and recolonization: their effects on the genetic differentiation of local populations. Evolution, 42: 995-1005.

Wakeley, J. 1998. Segregating sites in Wright's island model. Theor. Popul. Biol. 53: 166-174.

Whitlock, M.C., and McCauley, D.E. 1999. Indirect measures of gene flow and migration: $F_{\mathrm{ST}} \neq 1 /(4 \mathrm{Nm}+1)$. Heredity, 82: $117-125$.

Wiens, J.J. 2000. Reconstructing phylogenies from allozyme data: comparing method performance with congruence. Biol. J. Linn. Soc. 70: 613-632.

Wright, S. 1931. Evolution in Mendelian populations. Genetics, 16: $97-159$. 